\title{
Editorial: new chief editors
}

\author{
Theo C. M. Bakker • James F. A. Traniello
}

(C) Springer-Verlag 2011

Behavioral Ecology and Sociobiology (BES) is now in its 35th year of publication. During this time, it attained status as one of the leading journals for general, novel, and significant publications on behavioral biology (Fig. 1). BES was founded in 1976 by Hubert Markl (Konstanz, Germany) at a time when behavioral ecology and sociobiology were nascent disciplines. Edward O. Wilson's voluminous landmark "Sociobiology: the new synthesis" (Wilson 1975) was published only a year before, and Richard Dawkin's "The selfish gene" (Dawkins 1976) appeared the same year as the journal's foundation. In his foreword to the first issue of BES in 1976, the 90-year-old Karl von Frisch, who together with Niko Tinbergen and Konrad Lorenz was honored with the Nobel Prize in 1973, justified the development of the new journal: "One may regret the increasing specialization in research, but one cannot prevent it. It is a necessary consequence of the extension of our knowledge" (von Frisch 1976). von Frisch (1976) further explained that papers featuring organismal research in behavior had become lost in the Zeitschrift für vergleichende Physiologie, the prior venue for many articles of this genre. He added: "Most of the behavioral-physiological papers in the Zeitschrift für vergleichende Physiologie had a special character: although they centered on functional analysis, they usually also kept

T. C. M. Bakker $(\bowtie)$

Institute for Evolutionary Biology and Ecology,

University of Bonn,

An der Immenburg 1,

53121 Bonn, Germany

e-mail: t.bakker@uni-bonn.de

J. F. A. Traniello

Department of Biology, Boston University,

5 Cummington Street,

Boston, MA 02215, USA

e-mail: jft@bu.edu ecological adaptation, or, as we simply used to call it, biological significance, in mind. Results obtained from work on individual experimental animals were related to the animal's environment and thereby to more general questions in biology. Since this is the major scope of Behavioral Ecology and Sociobiology, the new journal will provide a new home for this kind of behavioral research and thereby should satisfy a real need" (von Frisch 1976). BES undeniably filled a significant gap through its focus on publishing studies on the ultimate functions and evolution of ecological adaptations of behavior in addition to studies on its proximate mechanisms. Montgomerie (1995) stressed the importance of BES this way: "As the first journal devoted exclusively to the emerging disciplines of Sociobiology and Behavioural Ecology, $B E S$ had an important part to play in bringing the field to its current prominence and vigour."

Hubert Markl was succeeded by K. Eduard Linsenmair (Würzburg, Germany) who became chief editor in 1988. He was followed in 1994 by Tatiana Czeschlik (Heidelberg, Germany) who has managed $B E S$ to this very issue, a marathon 17 years! We, Theo Bakker (Bonn, Germany) and James Traniello (Boston, USA), as the new chief editors, sincerely acknowledge Tatiana's dedication to $B E S$ and her skillful and motivated engagement. She maintained $B E S$ as one of the most prestigious journals in behavioral biology. To fully appreciate Tatiana's masterful accomplishment, we must recognize that her tenure as Editor-in-Chief for nearly two decades spanned a remarkably long period for this dynamic field of research, which has changed dramatically and had its primary themes extended continuously in multiple directions. This is illustrated, for example, by the shift from ethoecological analyses of foraging to research on sexual selection and behavioral syndromes. Also, studies on the function and evolution of behavior - an emphasis that distinguished behavioral ecology and sociobiology 
Fig. 1 Journal impact factors during the past 15 years of seven general journals of behavioral biology (Animal Behaviour, Behavioral Ecology, Behavioral Ecology and Sociobiology, Behavioural Processes, Behaviour, Ethology Ecology and Evolution, Ethology, and Journal of Ethology) that are not specialized on a particular research topic or animal group. Source: ISI Journal Citation Reports

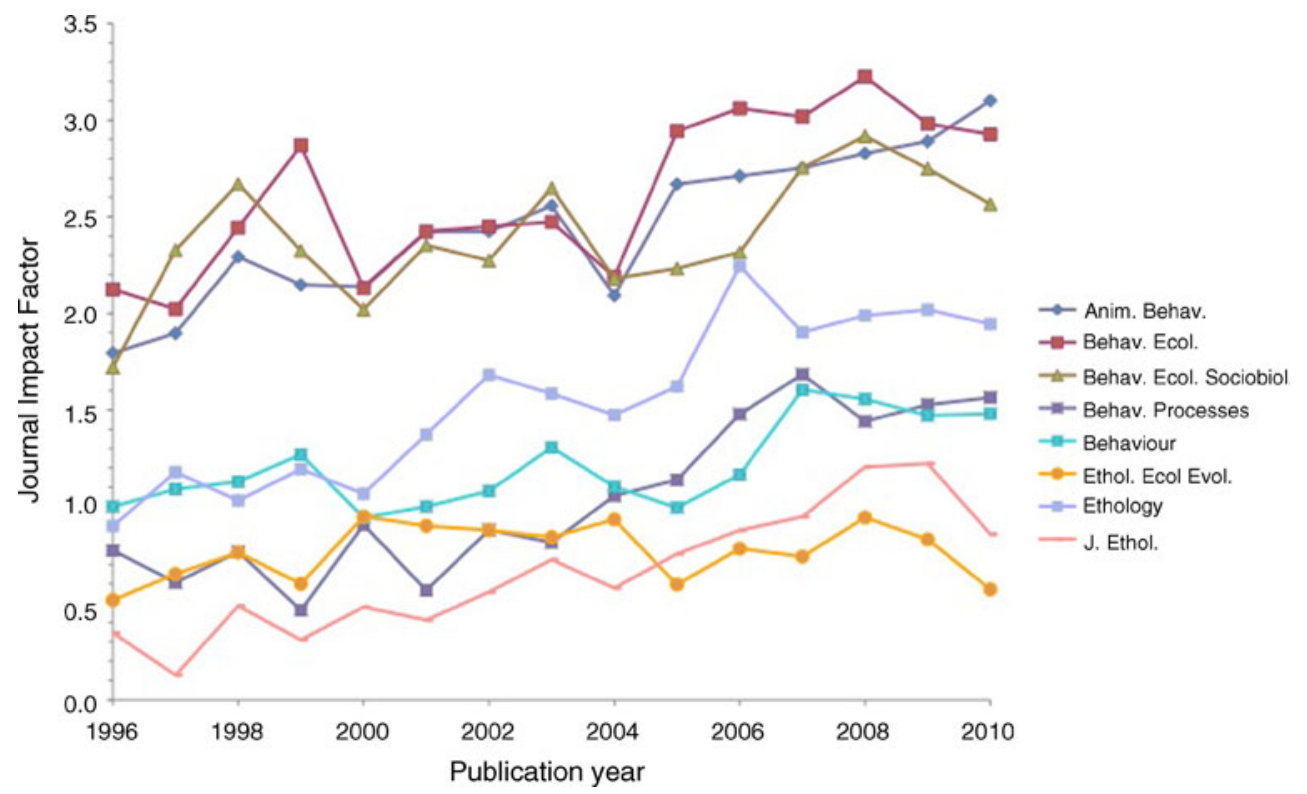

from ethology - gradually developed highly integrated approaches to examine proximate and ultimate factors at various levels of organization. This cross-disciplinary infusion is evident in many recent publications in BES.

The success of $B E S$ is not only due to excellent chief editors, efficient editorial assistants, and an influential and supportive publishing infrastructure, but is also largely dependent on the expertise of the editorial board, consisting now of 60 associate editors, all renowned experts in their fields, who select reviewers, validate evaluations, and make recommendations for publication. We sincerely wish that we can cooperate with the editorial board as successfully as Tatiana did and adapt opportunistically to the challenges and dynamics of this fascinating field of research in the -omics age, as molecular research fundamentally changes the intellectual landscape of behavioral biology and advances its goals. Following the focus of our own research, Theo will handle manuscripts dealing with vertebrates, while James will be responsible for submissions concerning invertebrates. We hope this dual chief editorship will further enhance the quality and efficiency of BES and promote the communication of Old and New World behavioral biologists. von Frisch (1976) concluded his foreword to the first issue of $B E S$ by expressing his hope that the newborn journal would "...flourish for the profit of science." Since its inception, over 4,000 articles have been published in $B E S$ and have received more than 19,000 citations during only the past 10 years of its three and one half-decade history. Today, the editorial staff process on average approximately 600 submissions per year. The Nobel Laureate's wish for success has without question been realized through the journal's academic influence. We are committed to continuing the tradition of excellence and innovation that has been so well established in $B E S$ and is now the legacy of this path-breaking journal.

\section{References}

Dawkins R (1976) The selfish gene. Oxford University Press, Oxford Montgomerie R (1995) Editorial: the impact of Behavioral Ecology and Sociobiology. Behav Ecol Sociobiol 37:145-146

von Frisch K (1976) Foreword. Behav Ecol Sociobiol 1:1-2

Wilson EO (1975) Sociobiology: the new synthesis. Harvard University Press, Cambridge 